\title{
COCRIAÇÃO DE VALOR NO ENSINO SUPERIOR PRIVADO: UMA ANÁLISE ETNOMETODOLÓGICA COM \\ ALUNOS DE ADMINISTRAÇÃO DE UMA UNIVERSIDADE DO SUL DO BRASIL
}

\author{
CO-CREATING VALUE IN PRIVATE HIGHER EDUCATION: \\ AN ETHNOMETHODOLOGICAL ANALYSIS WITH \\ MANAGEMENT STUDENTS FROM \\ A UNIVERSITY IN SOUTHERN BRAZIL
}

\author{
Recebido em: 04/06/2012 Aprovado em: 13/07/2012 \\ Avaliado pelo sistema double blind review \\ Editora Científica: Manolita Correia Lima
}

\begin{abstract}
FLÁVIO RÉGIO BRAMBILLAflaviobrambilla@terra.com.br CENTRO UNIVERSITÁRIO LA SALLE \& UNIVERSIDADE LUTERANA DO BRASIL
\end{abstract}

\author{
CLÁUDIO DAMACENA \\ PONTIFÍCIA UNIVERSIDADE CATÓLICA DO RIO GRANDE DO SUL
}

\section{RESUMO}

Os stakeholders que atuam no ecossistema do Ensino Superior privado possuem perspectivas de valor diferentes nas relações de troca. O entendimento de como o valor é criado pode contribuir para que ocorra uma efetiva cocriação de valor. Apesar da importância do tema para o desenvolvimento teórico da disciplina de marketing, Payne, Storbacka e Frow (2008) afirmam que pouco se conhece sobre como os consumidores se engajam na cocriação de valor. A questão que se coloca é por que as pesquisas realizadas até agora não respondem como esse processo da cocriação de valor pode ser gerenciado de forma a adequadamente atender as expectativas dos quatro principais públicos em termos acadêmicos (estudantes, professores, instituições de ensino e governo)? Nessa perspectiva, o presente estudo teve por objetivo aprofundar o entendimento dessa questão no contexto específico de uma Universidade, por meio da utilização da técnica das vignettes, situada no paradigma interpretacionista de ciência, mediante abordagem de Etnometodologia. Apesar de considerar apenas uma instituição, o estudo proporciona insights das práticas de cocriação no ensino superior e na formação de sentido pelos estudantes. Uma das considerações finais do estudo é que a predominância do valor funcional interfere na obtenção do valor epistêmico e social em múltiplas perspectivas.

Palavras-chave: valor; cocriação; etnometodologia; ensino superior.

\begin{abstract}
The stakeholders in the ecosystem of private higher education have different perceptions of value regarding exchange relationships. The understanding of how value is created can contribute to its effective co-creation. Despite the importance of the issue to the theoretical development of the marketing discipline, Payne, Storbacka and Frow (2008), argue that little is known about how consumers engage in co-creating value. The question that arises is why has the research conducted to date not answered how this process of co-creating value can be properly managed in order to meet the expectations of the four main stakeholders in academic terms (students, teachers, educational institutions and the government). Faced with this state of affairs, this study aims to further the understanding of this issue using the technique of vignettes, situated in the interpretational paradigm of science and using an ethnomethodological approach. Despite only involving one institution, the study provides insights into the practices of co-creation in higher education and in developing its students' sensibilities. One of the study's final considerations is that the prevalence of functional value interferes in the attainment of social and epistemic value from multiple perspectives. Keywords: value; co-creation; ethnomethodology; higher education.
\end{abstract}




\section{INTRODUÇÃO}

O aproveitamento de talentos dos clientes, por meio de experiências mais producentes, pode ser a alternativa para que organizações promovam serviço com características superiores em relação aos concorrentes (BENDAPUDI; LEONe, 2003). Prahalad e Ramaswamy (2004) relatam que o desejo do consumidor por interação é o que dá origem ao processo da cocriação. O local de encontro entre as partes (empresa e seus consumidores) é o mais relevante do mercado nessa contextualização do valor. Prahalad e Ramaswamy (2004) lembram que a ideia de interação não é nova e que é uma das fontes geradoras de valor. Nova é a definição de cocriação, como participação ativa do consumidor, gerando desempenho e valor superior no serviço, e uma posterior satisfação (PRAHALAD; RAMASWAMY, 2004).

Em alguns contextos, a cocriação não é apenas desejada, mas imprescindível à geração de valor. É o caso do ensino, em que instituição e alunos devem se preocupar com o resultado efetivo do serviço, mediante o desenvolvimento de competências esperadas, como cognição e raciocínio lógico. Por um lado, os estudantes estão preocupados em aprender (ou desenvolver as competências necessárias para o mercado de trabalho), não sendo reprovados. Assim, a experiência desse processo de cocriação será satisfatória. Pelo lado do professor, o objetivo é que os alunos desenvolvam as competências e que o avaliem de forma positiva. Para a instituição, é importante que os estudantes tenham desenvolvido as competências previstas, o que poderá ser provado em testes governamentais, e que o aluno não abandone a instituição e, ainda, possa ser um indicador de potenciais estudantes (na prospecção de alunos). Toda a sociedade necessita de profissionais hábeis à resolução das tarefas cotidianas, e, no caso dos negócios, exemplos como condução de empresas e organizações deixam evidente a importância dos melhores resultados cocriados na preparação destes futuros trabalhadores.

Apesar da importância do tema para o desenvolvimento teórico da disciplina de marketing e de a cocriação ser caracterizada pelo interesse mútuo e de maior atendimento, do ponto de vista dos consumidores, 
na melhoria do serviço, Payne, Storbacka e Frow (2008) afirmam que pouco se conhece sobre como os consumidores se engajam na cocriação de valor. A questão que se coloca é que as pesquisas realizadas até agora não respondem como esse processo da cocriação de valor pode ser gerenciado de forma a adequadamente atender as expectativas dos quatro principais públicos, em termos acadêmicos (estudantes, professores, instituições de ensino e governo). Nessa perspectiva, o presente estudo teve por objetivo aprofundar o entendimento dessa questão por meio da utilização da técnica das vignettes, situada no paradigma interpretacionista de ciência, mediante abordagem de Etnometodologia. Com base na intervenção realizada em uma Instituição de Ensino Superior (IES), o propósito deste estudo foi o de verificar, em contexto restrito, como a abordagem interpretacionista favorece o conhecimento da vida cotidiana dos estudantes e como estes se engajam na geração de valor acadêmico. A metodologia adotada não proporciona generalização para outras IEs e contextos, mas favorece no entendimento de como o engajamento influencia no valor. 


\section{COCRIAÇÃO DE VALOR NA EDUCAÇÃO SUPERIOR PRIVADA}

Nas relações de sala de aula ocorrem participação e interação, conceitos formadores do que se entende por cocriação. Menciona Vargo (2008, p. 2I2) que a "criação de valor sempre requer o envolvimento". Cocriar por meio de uma relação de troca se mostra uma fonte à geração de valores educacionais, no encontro de serviço do ensino superior privado (DONG; eVANS; ZOU, 2008; SILVA, 2003; CHUNG; MCLARney, 2000). Por exemplo, em Chung e McLarney (2000), mediante experiências conduzidas com os alunos, verificou-se que a sala de aula no sentido de vivenciar o aprendizado, por meio de interação, proporciona resultados superiores aos do ensino passivo, apesar das dificuldades para a condução do processo. A noção de vivenciar a sala de aula é para os autores uma forma de gerar resultados de aprendizagem superior, ou seja, maior geração de valor. A participação do aluno é critério básico na aprendizagem, em interação com o professor (GRANITZ; KOENING; HARICH; 2009; ATHANASIOU, 2007; KOTZÉ; PLESSIS, 2003; FASSINGER, 1995).

Cocriação no ensino, especialmente superior, implica o envolvimento dos estudantes na elaboração dos resultados (QIAN, 2006). Na sala de aula é possível cocriar por meio de atividades como sanar dúvidas, tanto discorrendo apontamentos pessoais, como por discussões e questionamentos, pela interação no ambiente ensino-aprendizagem. A atividade extraclasse também é importante na cocriação educativa. Kotzé e Plessis (2003) destacam a variedade de meios para cocriar em aula, sendo o valor resultante da noção de qualidade (ALVES; RAPOSO, 2007).

Entre as diversas formas de cocriação no ensino está a troca de experiências ou dialética, que inclui discussões sobre os formatos de ensino (SILVA, 2003) e se refere a uma tarefa complexa, exceto pela constatação de as atividades, as quais consomem mais tempo, serem as menos desejadas pelos acadêmicos (KARNS, 2005, 2006). Mediante estudos que adotam diferentes configurações de sala de aula e pelo uso de tarefas variadas e de maneira alternada, Karns $(2005,2006)$ não chegou a uma melhor estratégia de ensino. Estas experiências demonstram que a cocriação de valor requer 
a intervenção contextual, e que métricas quantitativas não conseguem identificar, com clareza, acerca dos antecedentes e consequentes da cocriação de valor. A dialética consiste na prática orientada à "reflexividade sobre o conhecimento" (LOPES; MAGESTE, 2008, p.4), um importante posicionamento neste contexto. Como mencionado por Lusch (2006), pessoas em isolamento, ainda que em interação com o meio, tendem ao estático, ao aprendizado contingente, mas "quando indivíduos interagem com outros e trocam", é constituída uma perspectiva de mudanças diferenciadas, cocriadas e de valor superior (LUSCH, 2006, p.24I).

Interatividade é essencial no cenário educacional, para que possa ocorrer o processo de ensino-aprendizagem, em especial pelo contato professor estudante. A interação na educação responde pela construção de conhecimentos desejados e necessários (ABRANTES; SEABRA; LAGES, 2007; CHUNG; MCLARNEY, 2000). Interação entre professor, aluno e grupos de estudantes é prática que pode ser cocriativa. O problema da falta de interatividade é apontado por Lopes e Mageste (2008, p.4), ao relatarem que, muitas vezes, no ensino prevalece "uma reprodução de conhecimentos, que são transmitidos como verdades absolutas". A cocriação de valor é uma estratégia para minimizar os aspectos condicionados no ensino.

Outra forma de cocriar é por meio da noção de Aprendizagem Colaborativa, atuação onde o aprendiz é direcionado à autonomia, o que lhe proporciona certa independência, bem como incentiva a colaboração e cooperação mútua (ATHANAsiou, 2007). O professor não deve ser o centro, mas, atuar como propulsor do aluno para que aprenda (facilitador). É notável a orientação para aprendizagem relacional, diferente daquela abordagem unidirecional centrada no professor, das escolas mais ortodoxas. Constitui atividade de cocriação na educação um serviço de aprendizagem orientado pela própria aprendizagem (DEBNATH; TANDON; POINTER, 2007). Para Reeve e Halusic (2009, p.I49), a aprendizagem cooperativa se refere a uma postura estudantil de "sentimento de uma comunidade de sala de aula”. Também a Aprendizagem Ativa, conceito muito similar, é parte da cocriação de valor na educação. Para Halbesleben e Wheeler (2009, p.I75), "estudantes que se engajam na aprendizagem ativa desempenham melhor 
nas aulas de negócios". Interessante é a percepção de que é preciso ser mais que consumidor do serviço educacional, mas um ator engajado na aprendizagem. Young (2005, p.36) diz que aprendizagem ativa "aumenta a percepção dos estudantes sobre sua autonomia percebida", e, assim, a motivação intrínseca favorece a aprendizagem.

Construtivismo e Teoria Crítica são aspectos tratados na educação, que perpassam a noção de cocriação, sendo muito próximos da aprendizagem colaborativa, em especial do construtivismo, o qual entende o professor como um facilitador, o orientador do estudante, para que seja desenvolvida a aprendizagem esperada (ATHANASIOU, 2007). Advém da busca coletiva pelas competências esperadas, ou seja, refere-se ao esforço conjunto na sala de aula entre professores e alunos para que os saberes de relevância, e maior capacidade crítica e analítica sejam desenvolvidas pelos estudantes. O construtivismo como a teoria crítica, requer postura ativa dos estudantes, cocriando saberes. Uma noção amplamente difundida é a de que é preciso elevar os estudantes para um nível em que se tornem mais críticos e reflexivos, com menor apego ao livro texto padronizado (CLEGG; STARBUCK, 2009).

Participação é um termo chave na aprendizagem cocriada. Salienta Fassinger (1995), que a participação do aluno na sala de aula é constituída por três variáveis, que são, respectivamente, o perfil da turma (que releva como é desempenhada a participação e quais as maneiras de aprender, de acordo com os perfis dos estudantes, o número de alunos na turma, etc.); dos alunos (trata dos aspectos individuais, porém globais, e envolve o gênero, faixa etária, mais as capacidades de absorção e compreensão do proposto pelo curso); e do professor (compreende interação com os alunos, qualificação e didática do professor, e como se desenvolve a comunicação entre o professor e seus alunos). Pode-se incluir uma variável adicional, não citada pelo autor, que diz respeito à relação entre Instituição (funcionários) e alunos.

Entender que "estudantes que controlam seu próprio aprendizado é a aceitação de que diferentes estudantes aprendem coisas diferentes em mesma experiência de aprendizagem" significa que estudantes aprendem de modos diferentes (RAMSEY; Fitzgibbons, 2005, p.338). Neste sentido, os 
mesmos autores ressaltam o papel do professor ao "criar o espaço para o aprendizado” (p.342). Ações de reciprocidade entre o docente e os estudantes, nos diálogos de aprendizagem, favorecem o estudante no alcance de seus objetivos centrais, como absorção de conhecimentos e boas notas (SIERRA, 20I0).

Como teoria integradora dos preceitos mencionados até esta parte do estudo, a Teoria das Trocas Sociais (Social Exchange Theory) contempla parte dos esforços de, com base na cocriação de valor, definir conceitos antes fragmentados ou ideologicamente carregados de vieses. A Teoria das Trocas Sociais (TTS) trata da interação interdependente ou contingencial, em relação às ações do outro. Dos aspectos da reciprocidade. Segundo Sierra (20I0, p.Io8), a "responsabilidade compartilhada é um componente crítico da aprendizagem do aluno", e essencial para a ocorrência das trocas sociais. Na concepção de Johnson e Selnes (2004), nos relacionamentos onde existe colaboração entre as partes, são conectadas as necessidades do demandante com as ofertas e recursos providos pelo ofertante. Estes princípios se aplicam bem no contexto da sala de aula, onde a interação e a reciprocidade favorecem o ensino. Esses autores abordam situações onde a troca social se realiza e, basicamente, identificam que o paradoxo entre colaboração e comportamento oportunista deve ser equacionado de maneira a minimizar ações negativas, centrando nos benefícios mútuos e de longo prazo. Os estudos empíricos demonstram que a colaboração gera resultados de maior valor.

Em poucas palavras, Cropanzano e Mitchell (2005, p.890) definem que a essência da TTs está no fato de as "trocas sociais constituírem ações contingentes na recompensa da reação dos outros, quais ao longo do tempo proporcionam recompensas mútuas advindas das transações e relacionamentos”. São relações de ganho mútuo, que podem ser fortalecidas. Caracterizada a noção de cocriação no ensino, o segundo momento deste estudo aborda seus resultados esperados, que são os valores obtidos nas relações, para posterior análise empírica. 


\section{CARACTERIZAÇÃO DE VALOR NO CONTEXTO EDUCACIONAL}

No ambiente educacional a geração de valor se relaciona com motivação, em especial referente aos estudantes (DEBNATH; TANDON; POINTER, 2007). O aspecto motivacional não se restringe aos discentes, sendo importante ao professor e à relação deste com seus alunos, viabilizando cocriação de valor (ABRANTES; SEABRA; LAGES, 2007). Valor e reciprocidade estão vinculados, mais especificamente à cocriação. Dizem Vargo, Maglio e Akaka (2008) que a troca mais complexa é a base para o valor de uso.

Oliveira (1996, p.2I) menciona que "a educação é sempre uma mediação valorativa, dirigida por valores, [...] que indica um determinado posicionamento". Valores são orientados por expectativas, consideram Voss, Gruber e Szmigin (2007), os quais qualificam a pessoa, transcendendo limites anteriores, e migrando do "ser" ao "dever ser".

A concepção de Valor adotada neste estudo é a proposta por Sheth, Newman e Gross (199I), relacionada com a Teoria do Comportamento de Escolha no Mercado. Esta corrente teórica entende que consumidores são orientados por valores multidimensionais de consumo, que "explicam porque os consumidores escolhem comprar ou não comprar (ou usar ou não usar)" um produto ou serviço (SHETH; NEWMAN; GROSs, I99I, p.I59). São propostos por Sheth, Newman e Gross (I99I) cinco valores de consumo (adaptáveis para outros contextos), que influenciam nos comportamentos decisórios. Entre estes valores, os autores observam três importantes condições ou regramentos, como destacado abaixo (p.I60):

- A escolha de consumo é uma função de múltiplos valores de consumo.

- Valores de consumo exercem diferentes contribuições para cada situação de escolha. - Os valores de consumo são independentes.

Os valores envolvidos são: o funcional (utilidade percebida e/ou atributos utilitários, como confiabilidade, durabilidade e preço); social (associação social com grupos e com a imagem social); emocional (sentimentos despertados pelas possibilidades e/ou alternativas, como, por exemplo, conforto ou associação com alguma etapa passada da vida); epistêmico (relacionado ao despertar de curiosidades, novidade ou conhecimento, como é o caso em situações novas, na curiosidade e no desejo de aprender); e 
condicional (relativo ao conjunto de situações específicas em um momento decisório, ou especificidades do contexto).

Entende-se que "escolhas são uma função de múltiplos tipos de valores de consumo" (FINCH, 2005, p.63). A Teoria do Comportamento de Escolha no Mercado "representa um radical afastamento da predominância dos modelos de comportamento do consumidor orientados por atributos", que são uma orientação para produto ( $\mathrm{FINCH}, 2005, \mathrm{p} .66)$. Neste sentido, Finch (2005, p.66) referencia que "escolhas de mercado são determinadas por múltiplos valores de consumo, mais do que por múltiplos atributos de produto”. Estes tipos de valores contribuem de acordo com a situação, respondendo por arranjos situacionais onde o "fenômeno multidimensional envolve múltiplos valores de consumo” (FINCH, 2005, p.66).

A teoria proposta, em I99I, do valor em múltiplas dimensões promove "benefícios econômicos e sociais" (FINCH; TROMBLEY; RABAS, I998, p.44) e consiste na evolução de uma visão de valor orientada para múltiplos atributos de produto para outra focada em múltiplos valores de consumo (finch; trombley; rabas, I998). Tanto o estudo de Sheth, Newman e Gross (I99I), quanto os nele inspirados de Finch (2005) e Finch, Trombley e Rabas (1998) identificaram, empiricamente, a pertinência dos valores multidimensionais no contexto de mercado. Na continuação desta seção, e com base nos estudos derivados de Costa (2007), os valores foram estudados no contexto do ensino superior brasileiro.

Emerge do estudo de Costa (2008, p.I52), que se utiliza dos múltiplos valores no contexto educacional, a questão: "Como os estudantes percebem valor no curso?”. Em busca de respostas, o autor utiliza uma perspectiva multidimensional do valor, composta pelas cinco dimensões. O [I] valor funcional (atributos do serviço, como utilidade e aspectos técnicos, associado com a qualidade e o preço); [2] valor social (referente aos relacionamentos entre os atores do serviço e os motivos de se engajar na atividade); [3] valor emocional (sentimentos e percepções, positivas ou negativas, acerca do serviço); [4] valor epistêmico (advindo da necessidade da geração do conhecimento e respostas às curiosidades) e; [5] valor condicional (motivos que fazem com que seja tomada uma decisão de consumo), tópicos estes 
relevantes ao contexto do serviço educacional (COSTA, 2008). A mesma fundamentação é utilizada nos estudos de Costa (2007); Costa, Soares e Brasileiro (2007); Costa e Oliveira (2008); Costa, Oliveira e Oliveira (2008); Costa e Mota (2008); e, Costa (2009).

Outra concepção de valor não conflitante com a supracitada é adotada neste estudo. Trata-se do valor de uso, especialmente na relação com o valor de troca, que fornece a base ou coexiste com o valor de uso na valoração de uma situação. O valor de troca é compatível com a Teoria das Trocas Sociais. Porém, na cocriação de valor, a ênfase migra ao valor de uso. Na concepção de Vargo (2007), o conceito de valor é utilizado para a mensuração de benefício recebido, e, neste contexto, o valor de uso está relacionado ao trabalho educacional e seu resultado. Já o valor de troca na contrapartida provida pelo aluno para estudar, ou seja, este valor aparece quando há uma relação financeira onde o pagamento de mensalidades, por exemplo, representa uma contrapartida diante dos recursos necessários para a promoção da aprendizagem, sejam os recursos humanos (professores, funcionários da IES) ou físicos (laboratórios de informática, biblioteca).

Adota-se neste estudo a noção de que tanto o valor de troca quanto o valor de uso, além de relevantes, são indissociáveis. Uma destas situações de simultaneidade é o contexto do Ensino Superior Privado, onde o valor transacional, relacionado ao valor nominal (preço) acerca da mensalidade paga pelo estudante, se repete a cada semestre. O valor nominal é equivalente ao conceito de preço de mercado (VARGo, 2007). Enquanto isso, o valor em uso ocorre à medida que o curso avança e o conhecimento é adquirido e acumulado pelo estudante mediante as disciplinas cursadas. Para Vargo (2007, p.54) uma "troca de trabalho é a fonte fundamental de valor real", ou seja, o valor é derivado da relação interativa (difícil de quantificar). Pela impossibilidade de mensuração do valor real, os conceitos de valor de troca e valor de uso são adotados. A relação entre estes conceitos de valor é estabelecida abaixo.

No trabalho de Vargo, Maglio e Akaka (2008), o valor de troca é relacionado aos bens e o valor de uso ao serviço. Discorda-se desta prerrogativa, e foi adotada a ideia evolutiva e complementar entre tipos de valor. Julga-se 
mais coerente definir que da prática cocriativa se originam relações de trocas complexas, as quais resultam no valor de uso. Conceitualmente, o valor de troca é difícil de ser mensurado, e é heterogêneo. Como mecanismos explicativos ao valor de troca, podem-se relevar as ideias de valor real (valor oriundo do trabalho), e valor nominal (representado pelo dinheiro), que ilustram a conexão entre os conceitos (VARGO; MAGLIO; AKAKA, 2008). Conforme concepção adotada nesta pesquisa, o valor de troca é observado também no contexto de serviço cocriado, porque existe trabalho proporcionado pelo fornecedor em troca de dinheiro advindo do cliente (no caso educacional, o professor trabalha como representante institucional, e o aluno paga suas mensalidades para estudar).

Com uma visão das faces do conceito Valor alinhada com a empregada neste estudo, Lusch (2007, p.266) menciona que uma "mais ampla visão do Valor deve incluir a ambos, valor de troca e valor de uso", como complementares e oriundos da interação. Para esse autor, a colaboração é uma tendência filosófica que poderá reger a dinâmica dos negócios. Conforme argumentos orientados pela complexidade do conhecimento e do dinamismo dos mercados, o valor é visto como algo que "não é criado e entregue, mas é cocriado pelos consumidores e demais parceiros de uma rede de valor" (LUSCH, 2007, p.266).

Segundo Vargo, Maglio e Akaka (2008, p.150), o Valor de Troca "é a mensuração negociada oferecida e recebida (ex. dinheiro e proposições de valor) entre parceiros de troca". O valor, seja qual for sua natureza, é determinado e criado em certo contexto. Igualmente referenciado pelos autores, "o processo de cocriar valor é orientado pelo Valor de Uso, mas mediado e monitorado pelo Valor de Troca" (VARgo; maglio; AKAKa, 2008, p.I50). Uma noção essencial é que a "criação de valor é sempre um processo colaborativo e interativo que ganha forma em contexto" (VARGO, 2009, p.374). Complementa o autor, destacando que criação de valor é situada em aspectos de tempo e espaço. Valor é decorrente da "combinação [adequada] de recursos mobilizados para a situação em particular" (vARGO, 2009, p.377), sendo a obtenção da desejada densidade relacional o reflexo da repetição 
dos encontros de serviço. O aspecto temporal é relevante, e um exemplo é a educação (VARGO, 2009).

Apesar de serem abordados, de maneira integrativa, os valores multidimensionais, o valor-de-troca e o valor-de-uso, embora relevantes e relacionados, não são claras alternativas para a representação do resultado de processos sociais complexos e interconexos. A solução conceitual, assim como a explicação que contempla a complexidade das relações sociais direciona ao que é intitulado por valor-em-contexto (uma evolução na ideia do valor-de-uso). Valor(es) não são apenas um resultado de causa e efeito, e tampouco de uma única relação entre variáveis. O valor é originário de um contexto social colaborativo, dizem Edvardsson, Tronvoll e Gruber (20II), no qual as estruturas sociais e os sistemas de significado entre os atores determinam e moldam o valor, por meio de interações atuais, que também podem refletir em percepções futuras (análises e reanálises dos significados e do que representa valor). Assim sendo, e com base nos conceitos de valor, o estudo adota uma noção integradora entre os tipos de valor, o que pode ser caracterizado como valor-em-contexto-social. 
METODOLOGIA DA PESQUISA: ETNOMETODOLOGIA COM ESTUDANTES

Para localizar a Etnometodologia dentro da concepção de ciência, uma alternativa relevante são os quatro paradigmas sociológicos de Burrell e Morgan (1979), ainda que sejam criticados com relação aos detalhes de sua concepção. Basicamente, Burrell e Morgan (1979), propuseram quatro paradigmas distintos, mas conectados, para analisar as teorias sociais: Interpretativo, Funcionalista, Humanista Radical e Estruturalista Radical. O presente estudo se limita ao paradigma Interpretacionista, com momentos de aproximação ao paradigma dominante, o Funcionalista. Em outras palavras, a aplicação de Vignettes segue a ideia de situações cotidianas para obter a percepção dos atores sociais envolvidos, mas a análise dos resultados segue lógica semelhante à da geração de categorias, como é prática tradicional dos estudos qualitativos orientados pelo paradigma positivista.

Destacam os autores uma concepção de mundo social, visto como um processo criado por meio das preocupações individuais, ou seja, os interesses dos indivíduos que moldam o interesse da maioria. Em parte, é possível verificar, junto aos discentes, o que estes esperam do ensino superior em Administração. Em linhas gerais, a "sociologia interpretativa é centrada no entendimento da essência do mundo de todo o dia", ou do "everyday world" (BURRELL; MORGAN, I979, p.3I). Esta perspectiva deixa evidente que Etnometodologia é uma intervenção complexa no mundo real, onde a significação é própria de cada participante, o que torna difícil uma aproximação das ideias de grupos de pessoas e contexto.

Salientam Daft e Weick (2005, p.74) que a "construção de interpretações acerca do ambiente é uma necessidade básica dos indivíduos e das organizações”. Na perspectiva dos autores, a interpretação é um dos aspectos distintivos dos seres humanos e de suas construções perante sistemas mais simples. O sociólogo Kenneth Liberman, mediante entrevista concedida via e-mail, para Sacrini (2009, p.673), destaca que a Etnometodologia "foi desenvolvida por Harold Garfinkel durante os anos 1950 e por seus muitos 
alunos nos anos 1960 e 1970, [com o foco nas] maneiras pelas quais o pensamento e o conhecimento são formalizados e transformados em um sistema social". Conforme o autor, sua preocupação consiste em entender o detalhamento do mundo cotidiano real em contexto. Esta abordagem de interação direta com as pessoas, que geram significados por meio dos seus atos, é a técnica utilizada com os estudantes neste estudo, mediante situações hipotéticas relacionadas com a sala de aula.

Garfinkel (2006, p.I2) destaca que a Etnometodologia possibilita "explicar as ações como uma contínua realização prática de seus membros". Os envolvidos são capazes de refletir e proporcionar explicações racionais de seu meio, o que representa a projeção das organizações socialmente estabelecidas, além de como o comportamento se desenvolve. A Etnometodologia deve procurar a ordenação das atividades cotidianas, não em busca da estruturação formal, mas para obter a compreensão do fenômeno junto ao ambiente em que ocorre. A mudança é uma variável que está inerente ao contexto, e faz com que as observações e relatos não sejam estáticos ou definitivos. Os indivíduos são investigados para que, mediante perspectivas individuais, seja possível a identificação das macroperspectivas.

Estas respostas podem ser extraídas de técnicas que envolvam, por exemplo, análise textual. No contexto interpretacionista, "as organizações são processos que surgem das ações intencionais das pessoas, individualmente ou em harmonia com as outras", uma vez que, a realidade social é complexa e predominantemente subjetiva (Vergara; CAlDAs, 2005, p.67). Destaca Paixão (1986) a Etnometodologia como uma corrente de pensamento oriunda de uma preocupação com as questões de intencionalidade e acerca dos significados imersos em subjetividade das ações dos seres humanos. Carolillo, Cortese e Donato (2008, p.2) entendem a Etnometodologia como uma "abordagem para o estudo da realidade, fruto da experiência", na adoção de métodos que proporcionem sentido e ordem social reconhecida por meio da intervenção junto aos grupos de interesse, em contextos por vezes inobservados. 
Se, por um lado, a aparente falta de rigor do ponto de vista positivista clássico pode ser identificada na estruturação flexível, em outros aspectos o método é mais robusto. Em um primeiro momento, responde ao problema, ou à utopia do "pesquisador neutro", já que o posicionamento do autor é definido e explicitado no próprio estudo. Como segundo aspecto de robustez, a proposta da etnometodologia se mostra mais realista para a investigação contextual, onde os fenômenos não podem ser separados dos contextos (tempo e espaço) nos quais ocorrem. Trata-se do que Granovetter (2007) define por embeddedness, acerca da dificuldade de criar fronteiras entre fenômenos. Tendo em vista a complexidade das atividades acadêmicas, a sala de aula não pode ser vista como um contexto estático.

A base de identificação do entendimento desejado advém da apresentação de situações complexas e incompletas, propositalmente estabelecidas, as quais requerem a abstração dos atores para a proposição de soluções/ procedimentos/ação (KIRSCHBAUM; HOELZ, 20Io). A Educação, por não ser um fenômeno parametrizado (cada turma, aluno, e professor são diferentes, e mudam ao longo do tempo), o que impede uma boa adequação para métricas numéricas, proporciona o emprego e a necessidade de uma abordagem interpretativa. Enquadra-se no cenário mencionado em Kirschbaum e Hoelz (20I0), porque requer o constante gerenciamento da tensão, pelo menos bivalente, representada no caso do presente estudo pela busca do aprendizado mútuo diante das necessidades de regulação.

Como base para a obtenção dos relatos necessários para análise, a técnica adotada está vinculada ao fornecimento de situações escritas, incompletas e complexas, e que requerem uma decisão do ator de interesse no estudo. Com base nas definições individuais, por meio de comparações sistemáticas, os resultados são obtidos. Estas situações escritas, ou Vignettes, estão "incompletas, exigindo a interpretação do indivíduo para dar sentido à situação” (KIRSCHBAUM; HOELZ, 20Io, p.8). Trata-se de situações educacionais, especialmente focadas nas relações da sala de aula entre alunos e professores (situações cotidianas). Estas relações podem ser entendidas como "sistemas de significados" (DAFT; wEICK, 2005, p.83). 
A perspectiva selecionada para análise é a visão do aluno, que é referência para todos os demais Stakeholders da Educação (Universidades, coordenadores, professores, futuros contratantes, comunidade, outros). DeShields Jr., Kara e Kaynak (2005, p.I29) mencionam que para mensurar educação é adequado utilizar "o acesso por meio de experiências de autopreenchimento". O objetivo é que seja empreendida uma situação hipotética de desequilíbrio ou desordem, que faça com que os respondentes expressem opiniões e impulsos.

Assim como adotado no estudo acerca da cocriação por Pini (2009), a abordagem de coleta de dados deste estudo também está orientada pelo entendimento essencial do cliente, que, neste caso, é o aluno graduando. A prerrogativa que orienta esta decisão recai em "mapear os comportamentos e atitudes por meio da cocriação", relevando papéis (PINI, 2009, p.63). Objetivase compreender "o fenômeno em seus detalhes" (CAROLILLO; CORTESE; DONATO, 2008, p.I3). Propõe-se a intervenção de pesquisa em contexto institucional (neste caso na Universidade), o que preconiza "propor uma ordem nas atividades concretas" (CAROLILlO; CORTESE; DONATO, 2008, p.I6). A ideia consiste na observação, ou busca de entendimento das ações, tendo em vista uma compreensão da racionalidade contextual.

Atendendo a uma das sugestões de Carolillo, Cortese e Donato (2008), a definição de relação dual serve como referência para a análise etnometodológica. O entendimento da percepção do aluno como cliente é o enfoque primário de pesquisa, relevando a dualidade da relação entre o professor (representante institucional da IEs) e os estudantes (os quais compõem a turma). Como destaca Heritage (1999), o preceito de investigação etnometodológica entende que tanto a análise das ações, quanto do conhecimento, gerado nos fenômenos sociais, estão intimamente relacionados. O conhecimento dos envolvidos nas situações sociais e seus relatos são importantes para que seja viável desenvolver qualquer possibilidade de explicação. Refere-se a "como os participantes criam, reúnem, produzem e reproduzem as estruturas sociais para as quais se orientam" (HERITAGE, I999, p.332). E contempla a "investigação sobre o modo como a inteligibilidade mútua da atividade ordinária é concretizada 
e mantida” (HERITAGE, I999, p.333). Destaca-se que os alunos escolhidos são da Administração.

Foram empregadas vignettes contendo situações que envolvessem a noção de valor aos estudantes, mediante supostas situações em sala de aula de diversas naturezas. Estas situações, assim como o roteiro podem ser obtidos mediante contato com o autor, e por questões de objetividade e espaço de texto não estão apresentadas neste artigo. As vignettes reproduzem cenários plausíveis de ocorrência na sala de aula e nos demais ambientes de interação dos alunos. Elas proporcionam um posicionamento crítico e a exposição de seus pensamentos e valores. Neste sentido, há projeções baseadas no cotidiano, vivenciado ou conhecido pelos estudantes. Trata-se de provocar os sentidos e as crenças de cada indivíduo.

Por meio das situações desenvolvidas, o objetivo de identificar as soluções dos atores assim como "empregados no fluxo da vida cotidiana [...], atribuindo sentido aos eventos, nas interações com os outros, como seres humanos participantes" do processo educacional (CAROLILLO; CORTESE; DONATO, 2008, p.5). Conforme os autores, o foco está na interação, a qual é constituída de uma relação dual entre realidades, que são cogeradas. Identifica-se que o completo entendimento da cocriação no ambiente da educação superior privada é uma meta inatingível, conforme destacam Vergara e Caldas (2005, p.7I) ao lembrar que "a realidade social, grupal, individual transborda de nossa capacidade de dela dar conta”. Apesar desta observação, uma aproximação contextual e temporal da realidade é viável, e pode auxiliar na constante busca de um entendimento mais geral e amplo dos fenômenos.

O emprego da técnica das Vignettes está associado com a ideia de avaliação profunda, que advém da consulta aos estudantes (por meio de pareceres - compreensões individuais e sentimentos diante das situações). Mais que alternativas de objetividade articuladas em termos de respostas, a técnica proporciona o estudo da percepção discente diante de seu entendimento acerca das situações, e mediante uma interpretação autêntica dos fatos, baseada em contextos de caráter formativo e não superficial e/ou passivo (GARCIA, 2009). 
As Vignettes foram aplicadas conforme orientação de Jenkins et al. (2010), que mencionam ser esta técnica uma maneira de obter as percepções sobre um contexto vivo, em que foram obtidas suas análises dos estudantes por meio do uso de formulário impresso, aplicado em sala de aula. Foram submetidas para apreciação dos estudantes de Administração as Vignettes, contemplando os elements abordados no referencial teórico. Foi pedida permissão para a aplicação aos alunos em sala de aula do formulário, o qual contou com caracterização demográfica, momento do curso e as questões pertinentes a serem abordadas, em especial, relacionadas com a cocriação de valor. Como exemplo de formulação destas sentenças para análise aberta dos alunos, segue a descrição de uma Vignette e sua breve explicação.

Vignette I5 (que trata da percepção do que representa valor no curso): "A ideia de valor é muito comum na vida em sociedade. Existem valores morais, afetivos, financeiros, pessoais, familiares, entre outros. O professor perguntou ao seu aluno quais os valores de estudar Administração, e ele não soube dizer. Ajude o aluno a responder." A própria sentença (Vignette) estabelece o que se quer saber do estudante, ao solicitar ajuda na definição. Na verdade, o que é feito pelo respondente é responder com base no que ele entende por valor (crenças), e este é o propósito da técnica, de que as pessoas projetem as suas verdades.

\section{CRITÉRIOS DE SELEÇÃO DA UNIVERSIDADE PRIVADA}

A Universidade Privada selecionada para o estudo é uma das maiores IES do Brasil. Além da facilidade de acesso ao pesquisador, o ambiente acadêmico é relevante por fazer parte de uma região com grande concentração de IES, o que favorece o juízo de valor dos respondentes. A acessibilidade foi fator preponderante, uma vez que a intervenção para estudo no ambiente acadêmico foi essencial tanto para a observação e vivência do pesquisador, como para as coletas de dados junto dos discentes, que foram conduzidas em ambiente natural.

Apesar de a diferença entre disciplinas ser um aspecto de preferências e entendimentos particulares dos estudantes, o objetivo do estudo foi identificar a cocriação, de maneira geral, ao longo do curso. Para isso, 
além de diferentes disciplinas fazerem parte da coleta dos dados, alunos de diferentes momentos no curso participaram do preenchimento das vignettes.

\section{CRITÉRIOS DE ESCOLHA DOS RESPONDENTES}

Entre as opções de respondentes, além dos alunos de Graduação, alunos dos cursos de Especialização, Mestrado e Doutorado poderiam ter sido selecionados. No entendimento do autor, o aluno do curso de Especialização em Administração provém de distintas áreas de conhecimento, portanto, nem sempre proporciona uma caracterização de negócios. Por outro lado, alunos de Mestrado e Doutorado são mais focados, homogêneos em interesse acadêmico e, deste modo, caracterizam um segmento de alunos que, fundamentalmente, devem cocriar, mediante produção acadêmica e demais tarefas (mais colaborativas e em grupos menores).

Os alunos do Bacharelado em Administração foram julgados como os mais adequados, porque, mesmo representando uma classe de conhecimento, são mais heterogêneos em termos de interesses, atitudes e entendimentos acerca do curso e da IEs da qual participam. Apesar da complexidade maior e dos riscos igualmente superiores, a determinação dos alunos de graduação pode ser a fonte mais rica para a identificação dos comportamentos em sala de aula, tanto em termos de cocriação, quanto para a rejeição destas práticas.

\section{CONSTRUÇÃO, VALIDAÇÃO E APLICAÇÃO DAS VIGNETTES (ABORDAGEM PROJETIVA)}

A ideia central da técnica projetiva atende ao que a Etnometodologia define como identificação dos sentidos, que os sujeitos definem de acordo com sua realidade. A construção da realidade, diferente das técnicas de pesquisa tradicionais, se dá por meio do senso comum, ou seja, do conjunto de respostas congruentes ou incongruentes acerca de um fato, o que identifica a maturidade do tópico em discussão e seu entendimento socialmente estabelecido. Conforme mencionado neste artigo, um dos indícios de validade da técnica e do instrumento de coleta (Vignettes) é a autoidentificação dos respondentes com as situações hipotéticas descritas. No estudo empírico com estudantes, os relatos providos demonstraram, 
em muitos momentos, a identificação dos respondentes com a situação proposta para análise. Na perspectiva dos estudos etnometodológicos, esta identificação entre sujeito e situação representa validade.

Em caráter mais próximo ao positivista, a descrição da elaboração dos formulários de coleta e a forma de interpretação das respostas deve ser mais bem delineada. Como primeira providência, o estudo teórico acerca da cocriação, em geral, e sua especificidade ao ambiente acadêmico, como forma de subsidiar a construção dos construtos de interesse. Posterior a esta etapa, e com base na experiência do pesquisador (um requisito no paradigma interpretativo e Etnometodologia), a identificação de situações reais ou plausíveis, descritas como Vignettes serão analisadas pelos respondentes, mediante a livre interpretação e liberdade para registrar suas posições. Cada situação é suportada por teoria, sendo que, para cada uma dessas teorias, é gerada, na situação, um conflito para gerar desconforto ou necessidade de escolha ao aluno. Depois de construídas, as situações hipotéticas (Vignettes) foram validadas por professor Doutor da área de Marketing, professores doutores de outras (sub)áreas da Administração e também submetidas para apreciação de estudantes de Mestrado e Doutorado em negócios.

A aplicação das Vignettes foi conduzida pelo pesquisador, na Universidade escolhida, em dias de aula normal, com o consentimento e apoio de professores e gestores. Por meio da interferência em dia cotidiano de aula, os alunos foram convidados a preencher manualmente o instrumento de pesquisa, composto por uma página de dados de caracterização, uma página de sentenças para análise e mais duas folhas pautadas em branco para as respostas. Como contrapartida do tempo disponibilizado, a IEs recebeu uma cópia da versão final do trabalho, para identificar as perspectivas dos discentes sobre cocriação. Os estudantes que participaram receberam por e-mail os resultados da pesquisa. A maioria dos estudantes forneceu endereços eletrônicos (campo de preenchimento opcional) para receber o documento final da pesquisa. O processo analítico foi conduzido pelo pesquisador, o qual digitou os pareceres fornecidos, e, posteriormente,conduziu as análises pela ordem das Vignettes. Participaram do estudo mais de roo estudantes, 
os quais não são identificados por nome em nenhum dos formulários coletados.

\section{FORMA DE APRESENTAÇÃO DA DISCUSSÃO DOS RESULTADOS: NARRATIVA}

Por se tratar de um estudo etnometodológico, o qual pressupõe que o entendimento da construção social ocorre em função das manifestações individuais integradas e interagentes, o conceito narrativo é adotado. Para Smith e Sperb (2007), o entendimento da sociedade consiste na interpretação das realidades dos indivíduos. O conjunto das realidades em um grupo forma a identidade deste sistema social particular. Neste estudo, configurase o Curso de Administração de uma IEs privada. A narrativa da cocriação desenvolvida neste artigo é centrada na experiência dos alunos, o que, para Dutra (2002, p.372), "remete àquilo que foi aprendido, experimentado, ou seja, aquilo que em algum momento, foi vivido pelo indivíduo". Por meio das vivências individuais coletadas nas situações (Vignettes), sistematicamente analisadas, a experiência dos estudantes, ainda que de maneira não generalizável, foi construída.

Apesar de representar apenas um determinado grupo de estudantes, os insights gerados são úteis, não apenas na compreensão do grupo investigado, mas para a condução de estudos em outras IEs. A estrutura narrativa foi selecionada para apresentação dos resultados do estudo em função do caráter dinâmico, seu aspecto humano, amplitude e plasticidade na apresentação da interpretação (BROCKMEIER; HARRÉ, 2003).

Por fim, destaca-se que o mapeamento dos respondentes foi delimitado, com base em diversos indicadores, como, por exemplo, quantidade de disciplinas cursadas, semestre e outros parâmetros. Em razão das limitações de páginas para o artigo, estes dados, bem como o detalhamento analítico foram suprimidos em favor dos conceitos centrais da investigação. 


\section{DISCUSSÃO DOS RESULTADOS}

Nesta etapa do artigo, estão apresentadas as principais resultantes do processo de intervenção etnometodológica. Para fins didáticos, os resultados estão mostrados em blocos conceituais, cujos títulos emergem dos resultados obtidos em campo. O desenvolvimento das categorias de discussão foi conduzido na relação entre teoria e resultados empíricos, com base na aplicação das vignettes, já que estas foram estabelecidas com influência dos preceitos teóricos, que orientam o tema cocriação de valor.

\section{VALOR INTANGÍVEL DA EDUCAÇÃO}

Uma das questões orientadoras da Lógica Dominante do Serviço reside na relação entre produto e serviço (VARGO; LUSCH, 2004). O uso das características comparativas foi adotado relevando as percepções de valor, comparando um valor de longo prazo com o valor de um tangível para utilização imediata. Basicamente, os aspectos discutidos são o valor educacional e a percepção da formação em Administração. Além da discussão entre valor de produto e de serviço, esta Vignette procura identificar as angústias da duração extendida de um curso superior diante das futuras recompensas, e estabelecer qual a compreensão dos futuros Administradores diante dos aspectos tangíveis e intangíveis do cotidiano (COSTA, 2008; COSTA; Oliveira; Oliveira, 2008; COSTA; SOARES; BRASILEIRO, 2007).

Embora a postura dominante manifeste o que expressa o respondente "Alunoi7", acerca da escolha pelo ensino superior como o "correto, pois uma graduação é um investimento, pois se adquire conhecimentos, que sendo bem aplicados futuramente irá gerar bens materiais". E que investir em tangíveis, como um automóvel, significa estar "investindo em algo no curto prazo, pois o bem se depreciará e futuramente não dará retorno", não foi obtida unanimidade. Há o que mencionou que o curso superior não proporcionou nenhum diferencial, o que preconiza a revisão de alguns aspectos: ou de seleção, ou de formação; ou de candidatos desprovidos de preparo para a educação superior, que estão frequentando as salas de aula, sem orientações claras acerca de seus papéis. A qualidade educacional pode não estar atingindo 
os patamares desejáveis. Seja qual for o aspecto é crítico e requer atenção. Para situar o leitor nesta atapa analítica, uma das vignettes propostas fez a comparação entre o dinheiro investido em produto diante de serviço, e descreveu uma situação para análise entre dois irmãos, um que optou pelo estudo e outro que optou por um veículo. No comparativo entre um bem tangível e de acesso imediato com um serviço intangível e de geração de valor no longo prazo, foi possível identificar a falta de noção de alguns estudantes acerca dos resultados educacionais. Esta constatação demonstra, com base na lógica do serviço e da cocrição de valor, que o ensino superior precisa uma definição mais clara do foco, bem como que é mportante resgatar o valor da educação como uma composição de múltiplos valores.

Uma postura interessante diante do ensino superior é a ideia de investimento. Os estudantes de Administração entendem que cursar o Bacharelado significa a busca por melhorias futuras, e associam este investimento com a noção de prosperidade. A ideia de aquisição futura de bens como resultado do conhecimento também é assinalada pelos respondentes, como é expresso no depoimento do "Aluno38”, ao referenciar que o...

... conhecimento não tem preço. Com o conhecimento e a sabedoria você pode ir além, mas comprando um carro, você não vai evoluir nada. Quem estuda tem mais oportunidades de crescimento na vida, e com isso vai poder adquirir muito mais do que quem não estuda (Aluno38).

\section{VALORES DISCENTES ACERCA DE ESTUDAR ADMINISTRAÇÃO}

Um ponto complexo do estudo, e também o mais relevante, consiste no entendimento do termo "Valor". Em função das dificuldades métricas, as mesmas que direcionaram este estudo para uma perspectiva interpretacionista, o objetivo desta situação foi coletar dos estudantes seus entendimentos acerca do valor, relacionado ao Curso de Administração (COSTA, 2008; COSTA; OLIVEIRA, 2008; COSTA; OLIVEIRA; OLIVEIRA, 2008; COSTA; SOARES; BRASILEIRO, 2007). A ideia do valor, ao estudar gestão, foi estimulada nos estudantes para que estes caracterizassem o seu significado, em termos sociais, morais e em escopo amplo (EDVARDSSON; TRONVOLL; GRUBER, 20II). 
Os resultados obtidos, surpreendentes até certo ponto, indicam fragilidade do curso em termos de direcionamento e clareza.

Basicamente, as respostas direcionam-se ao valor funcional, no sentido de aplicabilidade, o que se manifesta em pontos favoráveis e desfavoráveis na formação. Se, por um lado, é um curso com forte ênfase prática, relevando aspectos do valor de uso, (VARGo, 2007), por outro, fica clara a falta de preocupação com a bagagem intelectual, o que pode culminar em uma espécie de praticismo ou mecanização do conhecimento. A preocupação demasiada com o sucesso profissional acaba minimizando valores de ordem moral e ética (pouco referenciadas pelos respondentes). A perspectiva utilitarista é acentuada, em termos de busca de lucratividade, o que, por vezes, se sobrepõe aos valores sociais e emocionais, e deixa, em segundo plano, um tipo de valor essencial na formação, que é o epistêmico, justamente aquele que desperta a qualificação contínua e o senso de aprimoramento pessoal (FINCH, 2005; FINCH; TROMBLEY; RABAS, I998; SHETH; NEWMAN; GROSS, I99I).

A dificuldade em enxergar o Curso de Administração além de um investimento com retorno futuro ocasiona problemas de caráter formador. Docentes mais qualificados tendem a ilustrar a origem dos teoremas e as pesquisas na área, o que, para os alunos, em muitos casos, não representa o essencial, que são as noções para emprego prático. Assim sendo, são formados profissionais com pouca bagagem crítica, replicadores de conceitos e sem noção dos valores gerais da profissão (LOPEs; MAGESTE, 2008). O reflexo desta postura é uma profissão, por vezes, sem identidade, em que o graduado, assim como o leigo, age pensando em termos financeiros, sem relevar o complexo de valores fundamentais. Espera-se mais em termos de identidade de futuros Administradores, como o que Homans (1977, p.I6) chama de "desenvolvimento social do grupo", ou seja, outros tipos de valores característicos, além daqueles de ordem financeira ou técnicoutilitarista (SHETH; NEWMAN; GROSS, I99I).

A ênfase operacional explica dificuldades encontradas por docentes da graduação, em especial diante de trabalhos direcionados ao raciocínio abstrato. Apesar de a aplicabilidade ser importante, a capacidade de abstração é igualmente importante ao aluno. O ideal de preparação para o mercado 
de trabalho mascara a unidade fundamental de troca (VARGO; LUSCH, 2008; VARGO; LUSCH, 2004), que é o curso superior como uma preparação acima de tudo para a vida, não apenas voltada ao trabalho. Indícios indicam que os estudantes de Mestrado e Doutorado, em geral, são aqueles que ao longo da graduação desenvolveram uma visão além do praticismo e do retorno financeiro. Estudantes preocupados com a cultura tendem a se qualificar mais.

\section{RELAÇÃO ENCONTRADA ENTRE AS NOÇÕES DE COCRIAÇÃO E VALOR (COCRIAÇÃO DE VALOR)}

O resultado esperado da cocriação é a obtenção dos maiores valores possíveis para todos os envolvidos e interessados (stakeholders) no que está sendo feito (GUMMESSON, 2008). Na educação, os professores se beneficiam com estudantes mais empenhados, que trazem exemplos melhores e facilitam a condução das aulas. Os estudantes aprimoram seu conhecimento e extraem o máximo de valor do docente e da interação com os colegas. A IEs consolida sua imagem e, com isso, obtém resultados, como o aumento no número de alunos. A sociedade, além de ganhar cidadãos mais conscientes, também contará com profissionais de melhor nível humano e técnico/utilitário. Todavia, os resultados indicam uma limitação no entendimento de valor dos estudantes pesquisados. Identificou-se direcionamento prioritário aos valores funcionais (SHETH; NEWMAN; GROSS, I99I), e de uso (VARGO; MAGLIO; AKAKA, 2008). Se, por um lado, o valor de uso mostra que existe serventia ao que é aprendido, o valor funcional exagerado está representado pela forte orientação ao sucesso, acima de tudo, e à mecanização dos conhecimentos. Nestes termos, lucro, que é uma intenção positiva, acaba por ser uma questão problemática ou paradoxal quando desassociado dos valores éticos e morais. O desequilíbrio entre as noções/dimensões de valor é significativo.

O valor epistêmico, ou o valor do ser, é pouco destacado diante do ter. Mesmo que não exista um foco imediato ao "ter" no curso, o objetivo final está muito associado com esta perspectiva. Não se condena a ambição humana de crescimento, apenas quando ela rompe com parâmetros éticos e humanos, ou preceitos de conduta indispensáveis para que o convívio 
social seja equilibrado. A supremacia do valor funcional, declara Costa (2008), em detrimento ao epistêmico, favorece os saberes técnicos, mas deixa de lado uma importante face do conhecimento da Administração, que é a capacidade crítica (LOPES; MAGESTE, 2008).

Conforme o modelo proposto, os valores de um curso são absorvidos e se tornam inteligíveis aos estudantes por meio das percepções de desempenho e de qualidade. A percepção da qualidade do curso, e da IEs como um todo é tema recorrente nas pesquisas da gestão educacional. Como em outros tipos de serviço, no ambiente educacional, não se pode deixar de observar que o fator preço exerce certo impacto, mesmo que não seja fator preponderante na decisão dos estudantes. Critérios como a infraestrutura da IES em relação ao preço são percebidos pelos estudantes como uma orientação/referência de qualidade. Além da estrutura física da instituição, o corpo docente, assim como a reputação deste corpo docente e da própria IES representam um fator decisivo para a opção de estudo dos indivíduos. Como alternativa aos critérios anteriores, as respostas mostram que uma parte dos discentes acredita que a vontade e o desejo de sucesso do próprio aluno se sobrepõem às questões estruturais, ao corpo docente, e à própria reputação geral (imagem) da IEs. Quando o preço (em especial na relação entre custos e benefícios da escolha) é posto de lado, a imagem da IEs passa a representar o atributo mais relevante para a formação da qualidade percebida dos alunos e dos candidatos a se tornarem alunos da Universidade. A construção da imagem ou da marca de uma IEs se parece em muito com a construção em outros segmentos, já que a percepção de qualidade dos consumidores é um dos fatores do valor de marca. Por meio da qualidade na relação entre professor e estudantes, forma-se a qualidade percebida da IES, o que é complementado por outros aspectos, como a qualidade das instalações físicas. Há que se posicionar uma IEs com base em dois critérios elementares, respectivamente a qualidade de ensino e a estrutura física. Um fator que dificulta a qualidade da educação cocriada é o crescimento dos cursos que proporcionam apenas estrutura física, mas não a devida relevância acadêmica. 
COCRIAÇÃO DE VALOR NO ENSINO SUPERIOR PRIVADO: UMA ANÁLISE ETNOMETODOLÓGICA COM ALUNOS DE ADMINISTRAÇÃO DE UMA UNIVERSIDADE DO SUL DO BRASIL

Em razão da abrangência das vignettes e suas respectivas respostas, estas não constam em completude no artigo. Aos interessados, este material pode ser solicitado por e-mail. 


\section{CONSIDERAÇÕES FINAIS}

Finaliza-se o estudo com uma reflexão acerca da cocriação como um mecanismo de valor social (EDVARDSSON; TRONVOLL; GRUBER, 2OII). O ser humano "não realiza seu trabalho como ser isolado, mas sempre como membro de um grupo unido pela cooperação necessária à realização do trabalho, ou pela associação de amizades" (Homans, 1977, p.4I). Como a passagem acima estabelece, a interação é uma ferramenta social importante para a aprendizagem (VARGO, 2008). Em termos gerais, identifica-se que deve haver um esforço para migrar as perspectivas de formação dos estudantes de funcionalistas ou executores de tarefas para atores racionais e críticos, baseados em um amplo sistema de valores, com especial ênfase para as noções de que formação é uma perspectiva que visa além das tarefas, e deve contemplar as noções de responsabilidade social e de pensamento crítico.

Em linhas amplas sobre a cocriação, o estudo identificou que: [I] Alunos dispostos ao relacionamento requerem baixo esforço para estabelecer práticas de cocriação. [2] Os alunos que entendem o valor relacional podem ser convencidos por argumentação, a participar ativamente das atividades na sala de aula. [3] Os alunos individualistas podem ser motivados extrínsecamente, e parte deste individualismo advir da herança da educação inicial. Altos esforços podem ser necessários para cocriação quando esta situação é identificada. Em linhas amplas sobre o conceito de Valor, o estudo destaca que: [I] A predominância do valor funcional interfere na obtenção de epistêmico e social. [2] Diante desta constatação, a cocriação de valor deve direcionar os alunos de Administração para o interesse pelo conhecimento e desenvolvimento dos valores sociais, e deixar claro que utilidade é apenas uma das faces do curso e dos valores profissionais necessários. [3] Esta alteração pode contribuir para a formação de sujeitos mais críticos e conscientes.

Todavia, os resultados supracitados requerem algumas observações, baseadas tanto em limitações como em oportunidades para futuros estudos. Primeiramente, o objetivo deste artigo não foi generalização, o que requer aplicação de técnicas estruturadas e ampliação dos casos. O estudo 
proporciona insights relacionados ao contexto específico de investigação, o que representa um primeiro passo no entendimento da cocriação na educação superior de negócios. Em um segundo momento, as vignettes aplicadas servem ao propósito de captar a percepção dos estudantes, que servem de base para a criação de métricas, ainda que por nova intervenção metodológica. Por fim, é importante salientar que a cocriação de valor é um fenômeno complexo e multidimensional, o que dificulta a criação de medidas quantitativas. 


\section{REFERENNCIAS}

ABRANTES, J. L.; SEABRA, C.; LAGES, L. F. Pedagogical Affect, Student Interest, and Learning Performance. Journal of Business Research, v. 60, n. 9, p. 960-964, 2007.

ALVES, H.; RAPOSO, M. Conceptual Model of Student Satisfaction in Higher Education. Total Quality Management, v. 18, n. 5, p. 571-588, 2007.

ATHANASIOU, A. Developing Learner Autonomy through Collaborative Learning in a Higher Education Context. Journal of Business and Society, v. 20, n.1, p. 115-129, 2007.

BENDAPUDI, N.; LEONE, R. P. Psychological implications of customer participation in co-production. Journal of Marketing, v. 67, n. 1, p. 14-28, 2003.

BORUCHOVITCH, E. Escala de Motivação para Aprender de Universitários (EMA-U): Propriedades Psicométricas. Avaliação Psicológica, v. 7, n. 2, p. 127-134, 2008.

BROCKMEIER, J.; HARRÉ, R. Narrativa: Problemas e Promessas de um Paradigma Alternativo. Psicologia: Reflexão e Crítica, v. 16, n. 3, p. 525-535, 2003.

BURRELL, G.; MORGAN, G. Sociological Paradigms and Organisational Analysis. Aldershot, England: Ashgate, 1979.

CAROLILLO, G.; CORTESE, F.; DONATO, D. L'etnometodologia: Profili Teorici Ed Ambiti Applicativi. Dipartimento di Scienze Economico-Aziendali, Giuridiche, Merceologiche e Geografiche: Università degli Studi di Foggia. Quaderno, n. 2, p. 1-28, 2008.

CHIRKOV, V. I. A Cross-Cultural Analysis of Autonomy in Education: A SelfDetermination Theory Perspective. Theory and Research in Education, v. 7, n. 2, p. 253-262, 2009.

CHUNG, E.; McLARNEY, C. The Classroom as a Service Encounter: Suggestions for Value Creation. Journal of Management Education, v. 24, n. 4, p. 484-500, 2000.

CLEGG, S. R.; STARBUCK, W. H. Can We Still Fix Management? The Narrow Path towards a Brighter Future in Organizing Practices. Management, v. 12, n. 5, p. 332359, 2009.

COLOSSI, N.; CONSENTINO, A.; QUEIROZ, E. Mudanças no Contexto do Ensino Superior no Brasil: Uma Tendência ao Ensino Colaborativo. Revista da FAE, v. 4, $n$. 1, p. 49-58, 2001.

COSTA, F. J. da. A Influência do Valor Percebido pelo Cliente sobre os Comportamentos de Reclamação e Boca a Boca: Uma Investigação em Cursos de Pós-Graduação Lato Sensu. Tese (Doutorado em Administração) -Fundação Getúlio Vargas - Escola de Administração de Empresas de São Paulo, 2007. 
COSTA, F.J. da. Formação em Administração na Perspectiva do Aluno: Valor Percebido no Curso, Percepção do Prestígio e Identificação com a Profissão. Revista Ciências Administrativas, v. 14, n. 1, p. 151-163, 2008.

COSTA, F.J. da. Formação em Turismo na Perspectiva do Estudante: Valor Percebido no Curso, Percepção de Prestígio e Identificação com a Profissão. Revista Turismo: Visão e Ação, v. 11, n. 1, p. 3-22, 2009.

COSTA, F. J. da; LIMA, D. P.; ANDRADE, R. J. C. An Analysis of Business Administration Students Interest in the Area of Production and Operations. Journal of Operations and Supply Chain Management, v. 1, n. 2, p. 89-101, 2008.

COSTA, F. J. da; MOTA, K. C. N. Valor Percebido no Curso, Percepção do Prestígio e Identificação com a Profissão: Uma Análise Junto a Estudantes de Turismo. In: SEMINÁRIO DA ASSOCIAÇÃO NACIONAL DE PESQUISA E PÓS-GRADUAÇÃO EM TURISMO, 5., 2008, Belo Horizonte. Anais... Belo Horizonte, [s.n.], 2008.

COSTA, F.J. da; OLIVEIRA, L. G. L.; OLIVEIRA, D. M. de. Valor Percebido no Curso, Percepção do Prestígio e Identificação com a Profissão: Uma Análise Junto a Estudantes da Área de Negócios. In: ENCONTRO DA ASSOCIAÇÃO NACIONAL DE PÓS-GRADUAÇÃO E PESQUISA EM ADMINISTRAÇÃO, 32.,2008, Rio de Janeiro. Anais... Rio de Janeiro: [s.n.], 2008.

COSTA, F. J. da; OLIVEIRA, L. G. L. Valor Percebido no Curso, Percepção do Prestígio e Identificação com a Profissão: Uma Análise Junto a Estudantes de Administração e Contabilidade. Revista de Administração da UFSM, v. 1, n. 3, p. 453-468, 2008.

COSTA, F. J. da; SOARES, A. A. C.; BRASILEIRO, A. de S. B. Formação em Administração na Perspectiva do Aluno: Valor Percebido no Curso, Percepção do Prestígio e Identificação com a Profissão. In: ENCONTRO DE ENSINO E PESQUISA EM ADMINISTRAÇÃO E CONTABILIDADE, 1., 2007, Recife. Anais...[s.n.], 2007.

CROPANZANO, R.; MITCHELL, M. S. Social Exchange Theory: An Interdisciplinary Review. Journal of Management, v. 31, n. 6, p. 874-900, 2005.

DAFT, R. L.; WEICK, K.E. Por um Modelo de Organização Concebido como Sistema Interpretativo. Revista de Administração de Empresas, v. 45, n. 4, p. 73-86, 2005.

DEBNATH, S.C.; TANDON, S.; POINTER, L.V. Designing Business School Courses to Promote Student Motivation: An Application of the Job Characteristics Model. Journal of Management Education, v. 31, n. 6, p. 812-831, 2007.

DeSHIELDS Jr., O.W.; KARA, A.; KAYNAK, E. Determinants of Business Student Satisfaction and Retention in Higher Education: Applying Herzberg's Two-Factor Theory. International Journal of Education Management, v. 19, n. 2, p. 128-139, 2005.

DONG, B.; EVANS, K.R.; ZOU, S. The Effects of Customer Participation in CoCreated Service Recovery. Journal of Academy of Marketing Science, v. 36, n.1, p.123137, 2008. 
DUTRA, E. A Narrativa como uma Técnica de Pesquisa Fenomenológica. Estudos de Psicologia, v. 7, n. 2, p. 371-378, 2002.

EDVARDSSON, B.; TRONVOLL, B.; GRUBER, T. Expanding Understanding of Service Exchange and Value Co-Creation: A Social Construction Approach. Journal of the Academy of Marketing Science, v. 39, n. 2, p. 327-339, 2011.

FARANDA, W. T.; CLARKE III, I. Student Observations of Outstanding Teaching: Implications for Marketing Educators. Journal of Marketing Education, v. 26, n. 3, p. 271281, 2004.

FASSINGER, P.A. Understanding Classroom Interaction: Students' and Professors' Contributions to Students' Silence. Journal of Higher Education, v. 66, n. 1, p. 82-96, 1995.

FINCH, J.E. The Impact of Personal Consumption Values and Beliefs on Organic Food Purchase Behavior. Journal of Food Products Marketing, v. 11, n. 4, p. 63-76, 2005.

FINCH, J. E.; TROMBLEY, C. M.; RABAS, B. J. The Role of Multiple Consumption Values in Consumer Cooperative Patronage: An Application of the Theory of Market Choice Behavior. Journal of Marketing Management, v. 8, n. 1, p. 44-56, 1998.

GARCIA, J. Avaliação e Aprendizagem na Educação Superior. Estudos em Avaliação Educacional, v. 20, n. 43, p. 201-213, 2009.

GARFINKEL, H. Estudios en Etnometodología. Barcelona: Anthropos, 2006.

GRANITZ, N. A.; KOERNIG, S. K.; HARICH, K. R. Now It's Personal: Antecedents and Outcomes of Rapport between Business Faculty and their Students. Journal of Marketing Education, v. 31, n. 1, p. 52-65, 2009.

GUMMESSON, E. Extending the Service-Dominant Logic: From Customer Centricity to Balanced Centricity. Journal of the Academy of Marketing Science, v. 36, n.1, p. 15-17, 2008.

GRANOVETTER, M. Ação Econômica e Estrutura Social: O Problema da Imersão. RAEEletrônica, v. 6, n. 1, p. 1-40, 2007.

HALBESLEBEN, J.R.B.; WHEELER, A.R. Student Identification with Business Education Models: Measurement and Relationship to Educational Outcomes. Journal of Management Education, v. 33, n. 2, p. 166-195, 2009.

HERITAGE, J. C. Etnometodologia. In: GIDDENS, A.; TURNER, J. (Orgs.). Teoria Social Hoje. São Paulo: UNESP, 1999.

HOMANS, G.C. As Pesquisas na Western Electric. In: BALCÃO, Y.; CORDEIRO, L. $O$ Comportamento Humano na Empresa. 3.ed. Rio de Janeiro: FGV, 1977.

JENKINS, N.; BLOOR, M.; FISCHER, J.; BERNEY, L.; NEALE, J. Putting in the Context: The Use of Vignettes in Qualitative Interviewing. Qualitative Research, v.10, n. 2, p.175$198,2010$. 
JOHNSON, M. D.; SELNES, F. Customer Portfolio Management: Toward a Dynamic Theory of Exchange Relationships. Journal of Marketing, v. 68, n.1, p. 1-17, 2004.

KARNS, G. L. An Update of Marketing Student Perceptions of Learning Activities: Structure, Preferences, and Effectiveness. Marketing Education, v. 27, n. 2, p. 163-171, 2005 .

KARNS, G. L. Learning Style Differences in the Perceived Effectiveness of Learning Activities. Journal of Marketing Education, v. 28, n. 1, p. 56-63, 2006.

KIRSCHBAUM, C.; HOELZ, J. C. Mecanismos Mediadores entre Controle e Confiança. In: ENCONTRO DE ESTUDOS ORGANIZACIONAIS, 6., 2010. Anais... Florianópolis/ SC: ANPAD, 2010.

KOTZÉ, T. G.; PLESSIS, P. F. Students as "Co-Producers" of Education: A Proposed Model of Student Socialization and Participation at Tertiary Institutions. Quality Assurance in Education, v. 11, n. 4, p. 186-201, 2003.

LOPES, F.T.; MAGESTE, G.de S. Pedagogia Crítica: Repensando o Ensino de Estudos Organizacionais. In: ENCONTRO DE ESTUDOS ORGANIZACIONAIS, 5., Anais... Belo Horizonte: ANPAD, 2008.

LUSCH, R. F. Marketing's Evolving Identity: Defining Our Future. Journal of Public Policy \& Marketing, v. 26, n. 2, p. 261-268, 2007.

LUSCH, R. F. The Small and Long View. Journal of Macromarketing, v. 26, n. 2, p. 240-244, 2006.

OLIVEIRA, B. A. de. O Trabalho Educativo: reflexões sobre paradigmas e problemas do pensamento pedagógico brasileiro. Campinas: Autores Associados, 1996.

PAIXÃO, A. L. A Etnometodologia e o Estudo do Poder: Notas Preliminares. Anal. \& Conj., v. 1, n. 2, p. 93-110, 1986.

PAYNE, A.F.; STORBACKA, K.; FROW, P. Managing the co-creation of value. Journal of the Academy of Marketing Science, v. 36, n. 1, p. 83-96, 2008.

PINI, F. M. The Role of Customers in Interactive Co-Creation Practices: The Italian Scenario. Journal of Know Techn Pol, v. 22, n.1, p. 61-69, 2009.

PRAHALAD, C.K.; RAMASWAMY, V. Co-creating unique value with customers. Strategy \& Leadership, v. 32, n. 3, p. 4-9, 2004.

QIAN, B. Expectation, Service Quality, and Satisfaction in Higher Education: School of Management Strategic Marketing Group. MSc Theses (School of Management: Master of Science). Supervisor: Paul Baines. Cranfield University, p. 1-95, September, 2006.

RAMÍREZ, R. Value Co-Production: Intellectual Origins and Implications for Practice and Research. Strategic Management Journal, v. 20, n.1, p. 49-65, 1999. 
RAMSEY, V. J.; FITZGIBBONS, D. E. Being in the Classroom. Journal of Management Education, v. 29, n. 2, p. 333-356, 2005.

REEVE, J. M.; HALUSIC, M. How K-12 Teachers can put Self-Determination Theory Principles into Practice. Theory and Research in Education, v. 7, n. 2, p. 145-154, 2009.

SACRINI, M. Da Fenomenologia à Etnometodologia: Entrevista com Kenneth Liberman. Scientia e Studia, v. 7, n. 4, p. 669-679, 2009.

SHETH, J. N.; NEWMAN, B. I.; GROSS, B. L. Why We Buy What We Buy: A Theory of Consumption Values. Journal of Business Research, v. 22, n.1, p. 159-170, 1991.

SIERRA, J. J. Shared Responsibility and Student Learning: Ensuring a Favorable Educational Experience. Journal of Marketing Education, v. 32, n. 1, p. 104-111, 2010.

SILVA, M. Educação na Cibercultura: O Desafio Comunicacional do Professor Presencial e Online. Revista FAEEBA, v. 12, n. 20, p. 261-271, 2003.

SMITH, V. H.; SPERB, T. M. A Construção do Sujeito Narrador: Pensa-mento Discursivo na Etapa Personalista. Psicologia em Estudo, v. 12, n. 3, p. 553-562, 2007.

VARGO, S. L. Customer Integration and Value Creation: Paradigmatic Traps and Perspectives. Journal of Service Research, v. 11, n. 2, p. 211-215, 2008.

VARGO, S. L.; LUSCH, R. F. Evolving to a New Dominant Logic for Marketing. Journal of Marketing, v. 68, p. 1-17, 2004.

VARGO, S. L.; LUSCH, R. F. Service-Dominant Logic: Continuing the Evolution. Journal of the Academy of Marketing Science, v. 36, p. 1-10, 2008.

VARGO, S. L.; MAGLIO, P. P.; AKAKA, M. A. On Value and Value Co-Creation: A Service Systems and Service Logic Perspective. European Management Journal, v. 26, n.1, p.145-152, 2008.

VARGO, S. L. On a Theory of Markets and Marketing: From Positively Normative to Normatively Positive. Australasian Marketing Journal, v.15, n.1, p. 53-60, 2007.

VARGO, S. L. Toward a Transcending Conceptualization of Relationship: A ServiceDominant Logic Perspective. Journal of Business \& Industrial Marketing, v. 24, n.5/6, p. 373-379, 2009.

VERGARA, S. C.; CALDAS, M. P. Paradigma Interpretacionista: A Busca da Superação do Objetivismo Funcionalista nos Anos 1980 e 1990. Revista de Administração de Empresas, v. 45, n. 4, p. 66-72, 2005.

VOSS, R.; GRUBER, T.; SZMIGIN, I. Service Quality in Higher Education: The Role of Student Expectations. Journal of Business Research, v. 60, n. 9, p. 949-959, 2007.

YOUNG, M. R. The Motivational Effects of the Classroom Environment in Facilitating Self- Regulated Learning. Journal of Marketing Education, v. 27, n. 1, p. 25-40, 2005. 


\section{DADOS DOS AUTORES}

FLÁVIO RÉGIO BRAMBILLA flaviobrambilla@terra.com.br

Doutor em Administração pela Unisinos

Instituições de vinculação: Centro Universitário La Salle \&

Universidade Luterana do Brasil

Gravataí/RS - Brasil

Áreas de interesse em pesquisa: Marketing Estratégico, Lógica Dominante do Serviço, Cocriação de Valor, Marketing de Relacionamento e Recuperação de Serviço.

* Rua Antonio Francisco Fonseca, 39/201

Centro Gravatai/RS 94010-340

CLÁUDIO DAMACENA damacena.claudio@gmail.com

Doutor em Administração pela Universidade de Córdoba (Espanha)

Instituição de vinculação: Pontifícia Universidade Católica do Rio Grande do Sul Porto Alegre/RS - Brasil

Áreas de interesse em pesquisa: Marketing Estratégico, Marketing de Serviços e Comportamento consumidor. 